\title{
Developing consensus-based priority outcome domains for trials in kidney transplantation: a multinational Delphi survey with patients, caregivers and health professionals
}

\author{
Bénédicte Sautenet, MD, $\mathrm{PhD}^{1,2,3,4,5}$, Allison Tong, $\mathrm{PhD}^{1,2}$, Karine E Manera, MIPH ${ }^{1,2}$, \\ Jeremy R Chapman, FRCP6, Anthony N Warrens, MD7, David Rosenbloom ${ }^{8}$, Germaine \\ Wong, MBBS, PhD ${ }^{1,2,6}$, John Gill, MD $^{9}$, Klemens Budde, MD ${ }^{10}$, Lionel Rostaing, MD, PhD ${ }^{11}$, \\ Lorna Marson, MD, FRCS ${ }^{12}$, Michelle A Josephson, MD ${ }^{13}$, Peter $P$ Reese ${ }^{14}$, Timothy $\mathbf{L}$ \\ Pruett, MD ${ }^{15}$, Camilla S Hanson, BPsych (Hons) ${ }^{1,2}$, Donal O'Donoghue, MB ChB FRCP ${ }^{16}$, \\ Helen Tam-Tham, MSc ${ }^{17}$, Jean-Michel Halimi, MD, PhD ${ }^{3,4}$, Jenny I Shen, MD ${ }^{18}$, John \\ Kanellis, MBBS, PhD $^{19}$, John D Scandling, MD ${ }^{20}$, Kirsten Howard, PhD $^{1}$, Martin Howell, \\ PhD $^{1,2}$, Nick Cross, MD, PhD ${ }^{21}$, Nicole Evangelidis, BSocSc ${ }^{1,2}$, Philip Masson, MBChB, \\ $\mathrm{PhD}^{22}$, Rainer Oberbauer, MD, $\mathrm{PhD}^{23}$, Samuel Fung, MBBS, FRCP ${ }^{24}$, Shilpa Jesudason, \\ MD, PhD ${ }^{25,26}$, Simon Knight, MA, MB, MChir FRCS ${ }^{27}$, Sreedhar Mandayam, MD ${ }^{28}$, Stephen \\ P McDonald, MD, PhD ${ }^{25,26,29}$, Steve Chadban, FRACP, PhD $^{30}$, Tasleem Rajan, MD ${ }^{17}$, and \\ Jonathan C Craig, MBChB, $\mathrm{PhD}^{1,2}$
}

\begin{abstract}
${ }^{1}$ Sydney School of Public Health, The University of Sydney, Sydney, Australia ${ }^{2}$ Centre for Kidney Research, The Children's Hospital at Westmead, Westmead, Sydney, Australia 3University François Rabelais, Tours, France ${ }^{4}$ Department of Nephrology and Clinical Immunology, Tours Hospital, Tours, France ${ }^{5}$ INSERM, U1246, Tours, France ${ }^{6}$ Centre for Transplant and Renal Research, Westmead Hospital, Sydney, Australia ${ }^{7}$ School of Medicine and Dentistry, Queen Mary University of London, London, United Kingdom ${ }^{8}$ ESRD Network 18, Los Angeles, United States ${ }^{9}$ Division of Nephrology, University of British Columbia, Vancouver, Canada ${ }^{10}$ Department of Nephrology, Charité - Universitätsmedizin Berlin, Germany ${ }^{11}$ Department of Nephrology, Dialysis and Organ Transplantation, Centre Hospitalier Universitaire Rangueil, Toulouse, France ${ }^{12}$ Transplant Unit, University of Edinburgh, Edinburgh, United Kingdom ${ }^{13}$ Department of Medicine, The University of Chicago, Chicago, IL United States ${ }^{14}$ Renal Division, University of Pennsylvania Perelman School of Medicine, Philadelphia, PA, United States ${ }^{15}$ Department of Surgery, University of Minnesota, Minneapolis, United States ${ }^{16}$ Department of Renal Medicine, Salford Royal NHS Foundation Trust, Salford, United Kingdom ${ }^{17}$ Department Community Health Sciences, University of Calgary, Calgary, Canada ${ }^{18}$ Department of Nephrology, Los Angeles Biomedical Research Institute at Harbor-UCLA Medical Center, Los Angeles, CA, United States ${ }^{19}$ Department of Nephrology, Monash Health and Centre for Inflammatory Diseases, Department of Medicine, Monash University, Clayton, Victoria, Australia ${ }^{20}$ Department of Medicine, Stanford University School of Medicine, Stanford, CA 94305, USA ${ }^{21}$ Department of Nephrology, Christchurch Hospital, Christchurch, New Zealand ${ }^{22}$ Department of Renal Medicine, Royal
\end{abstract}

Corresponding author: Allison Tong, Centre for Kidney Research, The Children's Hospital at Westmead, Westmead, NSW, Sydney, Australia 2145, Tel: +61 298451467 Fax: +61 29845 1491, allison.tong@sydney.edu.au.

Disclosure: The authors declare no conflicts of interest. 
Infirmary of Edinburgh, Edinburgh, Scotland, UK ${ }^{23}$ Department of Internal Medicine, Division of Nephrology, University of Vienna, Austria ${ }^{24}$ Jockey Club Nephrology \& Urology Centre, Princess Margaret Hospital, Hong Kong ${ }^{25} \mathrm{Central}$ and Northern Adelaide Renal and Transplantation Service, Royal Adelaide Hospital, Adelaide, South Australia, Australia ${ }^{26}$ Faculty of Health and Medical Sciences, University of Adelaide, Adelaide, Australia ${ }^{27}$ Centre for Evidence in Transplantation, Nuffield Department of Surgical Sciences, University of Oxford, Oxford, UK ${ }^{28}$ Selzman Institute for Kidney Health, Section of Nephrology, Baylor College of Medicine, Houston, United States ${ }^{29}$ ANZDATA Registry, South Australia Health and Medical Research Institute, Adelaide, Australia ${ }^{30}$ Renal Medicine and Transplantation, Royal Prince Alfred Hospital, Sydney, Australia

\section{Abstract}

Background-Inconsistencies in outcome reporting and frequent omission of patient-centered outcomes can diminish the value of trials in treatment decision-making. We identified critically important outcome domains in kidney transplantation based on the shared priorities of patients/ caregivers and health professionals.

Methods-In a 3-round Delphi survey, patients/caregivers and health professionals rated the importance of outcome domains for trials in kidney transplantation on a 9-point Likert scale and provided comments. During Round 2 and 3, participants rerated the outcomes after reviewing their own score, the distribution of the respondents' scores, and comments. We calculated the median, mean, and proportion rating 7-9 (critically important), and analyzed comments thematically.

Results-1018 participants (461 [45\%] patients/caregivers and 557 [55\%] health professionals) from 79 countries completed Round 1, and 779 (77\%) completed Round 3. The top 8 outcomes that met the consensus criteria in Round 3 (mean $\geq 7.5$, median $\geq 8$ and proportion $>85 \%$ ) in both groups were graft loss, graft function, chronic rejection, acute rejection, mortality, infection, cancer (excluding skin) and cardiovascular disease. Compared with health professionals, patients/ caregivers gave higher priority to 6 outcomes (mean difference of 0.5 or more): skin cancer, surgical complications, cognition, blood pressure, depression, and ability to work. We identified 5 themes: capacity to control and inevitability, personal relevance, debilitating repercussions, gaining awareness of risks, and addressing knowledge gaps.

Conclusions-Graft complications and severe comorbidities were critically important for both stakeholder groups. These stakeholder-prioritized outcomes will inform the core outcome set to improve the consistency and relevance of trials in kidney transplantation.

\section{INTRODUCTION}

Over the past 50 years, remarkable progress has been made in kidney transplantation, largely owing to treatment advances and the growing number of trials in this area (1). Substantial reductions in rates of acute rejection have seen commensurate improvements in 1-year graft survival $(2,3)$. However, kidney transplant recipients depend on lifelong immunosuppressive therapy, which is associated with increased risks of life-threatening comorbidities including cardiovascular disease, diabetes, and cancer. An estimated $50 \%$ of patients have died with a 
functioning graft 10 years after transplantation, mostly due to the consequences of over immunosuppression $(4,5)$. While transplant may improve patient quality of life compared with dialysis, immunosuppression-related side effects can diminish these potential benefits (6). Such challenges draw attention to the need for evidence-informed shared decision making based upon trials that consistently report outcomes that are meaningful to both patients and clinicians (7).

Trials in kidney transplantation are often short-term, and important outcomes such as mortality, graft loss and kidney function are inconsistently and incompletely reported in randomized trials in kidney transplantation; with just $1 / 3$ reporting all 3 outcomes (8). Only $58 \%$ of trials report infection and $48 \%$ of trials report cancer (9). Less than $2 \%$ of trials of maintenance immunosuppression interventions report quality of life outcomes, with nearly all favoring the intervention (10). The heterogeneity of outcomes, many of which may not be directly relevant to patients, and selective reporting of outcomes diminishes the reliability and relevance of clinical trials for decision-making (11).

These problems are well recognized across many areas in healthcare, which has driven the development of core outcome sets, defined as an "agreed minimum set of outcomes to be reported in all trials" addressing a specific condition (12). The Standardized Outcomes in Nephrology (SONG) initiative was launched in 2014 to establish core outcomes across all stages of chronic kidney disease (CKD) including kidney transplantation (SONG-Tx) (13). As part of the SONG-Tx initiative, this study aimed to gain consensus among patients, caregivers and health professionals on critically important outcomes for trials in kidney transplantation. A core outcome set can improve the reporting of outcomes in trials permitting reliable comparisons of the effect of interventions across trials, and enhancing the usability and uptake of trial evidence in decision-making.

\section{METHODS}

\section{Study design}

The Delphi technique is a validated approach for establishing consensus on core outcomes (14-18) and consists of iterative surveys with anonymous responses to gain consensus among an "expert" panel $(19,20)$ (Supplementary File Figure S1).

\section{Participant selection and recruitment}

Adult patients/caregivers (aged 18 years or over) and health professionals with an interest or experience in kidney transplantation were eligible to participate. Patients/caregivers included kidney transplant recipients, patients with CKD Stages 1-5, or on dialysis, their caregivers, family members, and living kidney donors. Health professionals included physicians (nephrologists, surgeons, and psychiatrists), nurses, allied health professionals (psychologists, social workers, dieticians, and pharmacists), policy makers/regulators, researchers, and industry.

To be broadly inclusive, we used multiple recruitment strategies. Patients/caregivers were recruited by site investigators at participating hospitals, patient organizations worldwide (Supplementary File Table S1) using standardized invitation fliers, the SONG Network 
database by email, and via snowball sampling which included the use of social media. Health professionals were recruited through professional organizations (Supplementary File Table S1) via a standard invitation email to their membership list, investigator networks, and the SONG database. The invitation directed participants to register their email on the SONG website to receive an email invitation with the unique survey link. The University of Sydney (2015-228), Baylor College of Medicine (H-37406), University of Calgary (REB15-1875), Salford Royal NHS Trust (13082B) and Sydney West Area Health Services (HREC2009/6/4.15) provided ethics approval.

\section{Data collection}

Selection of outcome domains-We identified the outcome domains from a systematic review of outcomes reported in trials in kidney transplant recipients, studies on kidney transplant recipient preferences for outcomes (21), and studies focusing on patient-reported outcomes (22-23). The list of outcomes was reviewed by the investigators, and piloted among 8 patients. We programmed and administered the survey online using LimeSurvey from February to June 2016 (24). The survey was conducted in English.

Round 1-Round 1 included 35 outcome domains (Supplementary File Table S2). Participants rated the importance of each outcome domain on a 9-point Likert scale using the GRADE scale (Rating 1 to 3 indicated "limited importance", 4 to 6 "important, but not critical," and 7 to 9 "critical importance") (25). Free text boxes were provided for comments and participants could suggest new outcomes. Outcomes with a mean and median of more than or equal to 7 were taken through to Round 2. New outcomes suggested by more than $10 \%$ of the participants would be included in the next round.

Round 2-Participants rerated each outcome and provided (optional) comments. Participants reviewed their own score from Round 1, and the distribution of the group responses on a column graph displayed by patients/caregivers, health professionals, and the weighted score of both groups combined. Participants were shown the comments from patients/caregivers and health professionals. If outcomes had a mean and median score of more than 7, and more than $50 \%$ of participants rated the outcome 7 to 9 , we retained those outcomes for Round 3.

Round 3-Participants were provided with their own score, the group responses and comments as per Round 2 and asked to rerate the final set of outcomes. To assess the relative importance of outcomes, participants also completed a forced ranking exercise and ordered outcomes in order of importance using a drag and drop function (26).

\section{Data analysis}

Quantitative analysis-We assessed the mean, median, and the proportion of participants who rated 7 to 9 for each outcome across all rounds, and separated by patients/caregivers and health professionals. We compared the mean difference in rating scores between both stakeholder groups with a Wilcoxon signed rank test or a t test, significance at $p<0.05$. We performed subgroup analysis by country and age. For the forced ranking scores, we calculated the median and interquartile range (IQR) to determine the rank of each outcome. 
Statistical analyses were undertaken using R version 3.2.3 ( $R$ Foundation for Statistical Computing, Vienna, Austria).

Definition of consensus for core outcomes-An a priori definition of consensus was not possible because of the unknown distribution of scores for the outcome domains. For feasibility, we aimed to identify the top 3-5 outcome domains indicated as critically important by both stakeholder groups. "Consensus" for a critical outcome domain was based on both stakeholder groups having a median score of greater than or equal to 8 , a mean score greater than or equal to 7.5, the proportion of participants rating the outcome as 'critically important' being greater than or equal to $75 \%$, and a median score of less than 10 in the forced ranking question.

Qualitative analysis-We imported the comments into HyperRESEARCH (Version 3.7, Randolph MA United States) software for qualitative data analysis. Using thematic analysis, KEM coded the text and inductively identified themes focusing on reasons for ratings, changes in ratings across rounds, and differences between stakeholder groups. Two investigators (BS and AT) who read the qualitative data, reviewed the preliminary analysis to ensure that the themes captured the range and depth of data.

\section{RESULTS}

\section{Participant characteristics}

In round 1, 1018 people from 78 countries participated, of whom 461 (45\%) were patients/ caregivers and 557 (55\%) were health professionals. Round 2 was completed by 844 (83\% response rate) participants from 70 countries, of whom 387 (46\%) were patients/caregivers and 457 (54\%) were health professionals. Round 3 was completed by 779 (77\% response rate) participants with $360(46 \%)$ patients/caregivers and $419(54 \%)$ health professionals from 68 countries. Overall, the participant characteristics were consistent from rounds 1 to 3 (Table 1 and 2).

Of the 360 patients/caregivers who completed all 3 rounds, 251 (69\%) were kidney transplant recipients, $32(9 \%)$ patients on dialysis, 17 (5\%) patients not on any kidney replacement therapy, 35 (10\%) living kidney donors, and 27 (7\%) were caregivers/family members. The patients/caregivers were from 21 countries. Of the 419 health professionals, $281(59 \%)$ were nephrologists, 61 (13\%) researchers, and 49 (10\%) nurses. Health professionals were from 64 countries.

\section{Ratings and ranking}

Round 1-The mean and median scores for each of the 35 outcome domains and proportion of participants scoring outcomes as 7-9 (critical importance) for each outcome are included in the Supplementary Table S3. For patients/caregivers, the 4 outcomes with the highest mean scores were: graft loss (8.3, standard deviation [SD] =1.3), graft function (8.1 [1.3]), chronic graft rejection (7.9 [1.5]) and acute graft rejection (7.9 [1.6]). For health professionals, the 4 top outcomes were graft loss (8.4 [1.8]), mortality (8.3 [2.3]), graft function (7.9 [1.7]), and chronic graft rejection (7.8 [1.6]). Thirteen outcomes had a mean or

Transplantation. Author manuscript; available in PMC 2018 August 01. 
median score of less than 7 among both groups and were excluded from round 2

(Supplementary Table S3). None of the new outcomes were suggested by more than $10 \%$ of the participants (Supplementary Table S4).

Round 2-The mean and median scores for each of the 22 outcome domains and proportion of participants scoring the outcome as 7-9 (critical importance) for each outcome are included in the Supplementary Table S5. For patients/caregivers, the 4 outcomes with the highest mean scores were: graft loss (8.6 [0.8]), chronic graft rejection (8.5 [0.9]), graft function $(8.5[1.0])$ and acute graft rejection $(8.2[1.2])$. For health professionals, the 4 highest were graft loss (8.8 [1.5]), mortality (8.7 [1.1]), graft function (8.4 [1.0]), and chronic graft rejection (8.3 [0.9]). Six outcomes were excluded from round 3 as they had a mean and median score $\leq 7$ with less than $50 \%$ of the participants rating the outcome 7 to 9 (Supplementary Table S5).

Round 3-The mean and median score for each of the 16 outcome domains and the proportion of participants scoring the outcome as 7-9 (of critical importance) for each outcome are shown in Supplementary Table S6 and Figure S2. For patients/caregivers, the 4 outcomes with the highest mean scores were: graft loss (8.8 [0.6]), chronic graft rejection (8.6 [0.8]), graft function (8.6 [0.9]) and acute graft rejection (8.3 [1.0]). The mean scores by age group are shown in Table S7. For health professionals, the 4 highest were graft loss (8.9 [0.4]), mortality (8.8 [0.7]), graft function (8.6 [0.7]), and chronic graft rejection (8.5 [0.8]). Median rank scores (shown in Supplementary Figure S3) and Inter Quartile Ranges (IQR) were calculated from the forced ranking exercise. Based on the median rank scores and IQR, the 4 most important outcomes for patients/caregivers were graft loss (median score 3 [IQR 2-5]), chronic graft rejection (3 [2-5]), acute graft rejection (4 [2-6]) and graft function (5 [3-7]). For health professionals, the 4 most important were graft loss (3 [2-3]), mortality (3 [1-4]), graft function (5 [3-6]), chronic graft rejection (5 [3-6]).

Consensus-Eight of the 16 outcomes in round 3 met all 4 consensus criteria (mean rating $\geq 7.5$, median rating $\geq 8$, proportion of 7 to 9 rating scores $\geq 75 \%$, median rank score $<10$ ) in both stakeholder groups. These were: graft function, mortality, acute graft rejection, chronic graft rejection, graft loss, infection, cardiovascular disease and cancer (non-skin). Figure 1 depicts all 16 outcomes from Round 3 against the 4 consensus criteria.

\section{Changes in scores from round 1 to 3}

The 8 outcomes that fulfilled the consensus criteria were the same across the 3 rounds for both stakeholder groups. For patients/caregivers, the mean rating scores for 15 of the 16 outcomes in round 3 increased and only the score for blood pressure decreased. For health professionals, the mean scores for 14 of the 16 outcomes in Round 3 increased. The results are presented in Figures 2 and 3.

\section{Differences between stakeholder groups}

The mean differences in ratings between both stakeholder groups across all rounds are shown in Figure 4. Patients/caregivers rated 11 outcome domains higher than health professionals: skin cancer (mean difference 1.0, $\mathrm{p}<0.001$ ), surgical complications $(0.7$, 
$\mathrm{p}<0.001)$, cognition $(0.6, \mathrm{p}<0.001)$, blood pressure $(0.6, \mathrm{p}<0.001)$, depression $(0.5$, $\mathrm{p}<0.001)$, ability to work $(0.5, \mathrm{p}<0.001)$, acute graft rejection $(0.3, \mathrm{p}<0.001)$, non-skin cancer $(0.3, \mathrm{p}<0.001)$, infection $(0.3, \mathrm{p}<0.001)$, diabetes $(0.2, \mathrm{p}<0.001)$, and chronic graft rejection $(0.1, \mathrm{p}=0.022)$. Two outcomes were rated higher by health professionals: mortality $(0.4, \mathrm{p}<0.001)$ and hospitalization $(0.2, \mathrm{p}=0.033)$. The subgroup analyses for countries with more than 10 participants for outcomes rated higher by patients/caregivers (ie, outcomes with a mean difference of 0.5 or more) are shown in Table S8. There were no differences in the rating of these outcomes across countries except for cognition and depression.

\section{Themes from comments}

We identified 5 themes that reflected the reasons, changes and differences in the rating of outcomes: capacity to control and inevitability, personal relevance, debilitating repercussions, understanding and gaining awareness of risks, and addressing critical knowledge gaps. The description of the themes in the following section applies to both stakeholder groups unless otherwise specified, and supporting quotations are provided in Table 3.

Capacity to control and inevitability-Although participants recognized some outcomes such as blood pressure or skin cancer as important, these were rated of relatively lower importance if perceived as preventable, treatable, or non-life threatening. Across rounds, some participants decreased their ratings as they realized that certain outcomes could be feasibly improved - "I changed my answer. It's critical, but experienced surgeons make miracles happen." For patients, some outcomes were considered of lower importance if they were inevitable - "death comes to us all, but maintaining quality of life while living is more important."

Personal relevance-Participants considered the importance of outcomes in terms of the patient/caregivers' life stage, health status, and personal experience, and this was maintained across rounds. For example, patients who were retired rated ability to work of lower importance. However, some recognized that fertility and ability to work would be an important outcome for younger people, and thus adjusted their rating to be "sympathetic" to other patients in different stages of life.

Debilitating repercussions-Outcomes seen as severely debilitating, distressing, or which would lead to serious comorbidities or hospitalization were rated of higher importance. For patients, graft loss meant a return to dialysis, which was described as "devastating" and "worse than the fear of death." In contrast, some health professionals agreed that losing the graft was a "main hard endpoint", but "relative to death [it] cannot receive the highest rating."

Understanding and gaining awareness of risks-Patients/caregivers increased their ratings across rounds as read comments from health professionals and became "enlightened" about the risks of outcomes. Outcomes were rated higher if they learned that it was associated with a greater risk of graft loss and chronic graft rejection - "I'm naturally going to increase my rating if the pro[fessional]'s think it's critical." Health professionals 
expressed appreciation and "respect" of the importance of outcomes to patients, namely psychosocial and disabling outcomes - "underestimated the importance based on patient feedback."

Addressing critical knowledge gaps-Participants recognized the unresolved challenges of preventing complications including rejection, graft function, cancer, infection, and diabetes, which prompted them to assign higher importance to these outcomes. Health professionals suggested that "long standing issues" that lacked evidence should also be high priorities for research and would benefit patients eg, ability to work.

\section{DISCUSSION}

The outcomes of critical importance for patients/caregivers and health professionals were graft loss, graft function, acute graft rejection, chronic graft rejection, mortality, cardiovascular disease, infection, and cancer (non-skin). Overall, the results were congruent between the two stakeholder groups, with the same top 8 outcomes. Graft-related outcomes comprised the top 4 for both patients/caregivers and health professionals, consistent with research priority setting studies (27-29). For patients, returning to dialysis was a devastating consequence of graft failure that could even be worse than death. The critically important outcomes based on consensus echo the foremost challenges in transplantation, specifically, balancing graft survival and graft complications, with the risk of severe medical comorbidities (27,30-34). The other outcomes that remained in the final round of the Delphi survey were mostly clinical complications, of which skin cancer, diabetes, surgical complications, cognition, and depression, were more important to patients/caregivers than they were to health professionals. Only 1 patient-reported outcome (ability to work) remained in round 3. This may reflect the gains in quality of life owing to kidney transplantation compared with dialysis, and that various dimensions of quality of life are implicit in graft outcomes and severe medical complications.

While mortality was rated critically important for both stakeholder groups, the mean rating score was higher for health professionals (8.3) and ranked second after graft loss, compared with patients/caregivers (7.6) where mortality ranked fifth (below all the graft related outcomes). This discrepancy could be due to differences in how patients/caregivers and health professionals conceptualize death. Free text comments suggest that patients accept death as unavoidable, beyond their control, and therefore place greater importance on having a good quality of life. For health professionals, patient survival was entrenched as their primary goal of care and deemed to be the principal hard endpoint (35).

Patients and caregivers placed greater importance on skin cancer, surgical complications, cognition, depression, blood pressure, and ability to work, compared with health professionals. The discrepancy in the prioritization of skin cancer may reflect geographical variations in the risk of skin cancer. We noted that patients/caregivers in countries with public campaigns for skin cancer prevention (United States, South Africa, Canada and Australia (36-39)), on average, rated skin cancer as critically important. Patients and caregivers expressed some fears about surgical complications, which may in part explain the higher rating. Whilst mental health and cognition outcomes improve after kidney 
transplantation, kidney transplant recipients are still at higher risk of cognitive impairment compared with the general population $(34,40-42)$. This may also be attributable to the growing population of older recipients in whom cognitive decline is more prevalent (43). Such problems remain under-recognized and few studies have addressed the effect of transplantation on cognitive function $(44,45)$. Blood pressure was initially rated highly, then decreased from round 1 to 3 . From the comments, we speculate that patients became more aware that blood pressure was manageable after reading comments from health professionals. Ability to work was critically important to patients/caregivers across countries, some of whom regarded working as a key measure of transplant success and return to normality.

Unlike for hemodialysis, patient-reported outcomes were not prioritized as highly in kidney transplantation. In the Delphi survey on hemodialysis, ability to travel and dialysis-free time were rated markedly higher by patients/caregivers than providers (17). Also, a wider range of lifestyle patient-reported outcomes remained critically important in hemodialysis for both stakeholder groups (ability to travel, dialysis-free time, postdialysis fatigue, mobility, fatigue, social impact, pain, and ability to work). These differences between hemodialysis and kidney transplantation may be indicative of the considerable improvements in quality of life achieved through kidney transplant. The overriding goal for kidney transplant recipients was to protect their graft to maintain their quality of life and remain free from the constraints and distress of dialysis $(46,47)$.

The consensus between patients/caregivers and health professionals supports the inclusion of graft outcomes and medical comorbidities in a core outcome set for kidney transplantation. However, the, dominant focus on the clinical challenges of kidney transplantation may have led to patient-reported outcomes being assigned a lower rating score. For example, as quality of life is markedly improved by transplantation, compared to dialysis, it could be assumed as a given provided the graft continued to function. This is pertinent given the increasing emphasis on including patient-reported outcome measures in trials, to assess how patients feel and function (48). Moreover, patient-reported outcome measures are now required by regulators such as the U.S. Food and Drug Administration to support claims for medical product labeling (49). Thus, we recommend to include a patient-reported outcome domain in the core set. Although "ability to work" was the highest rated patient-reported outcome domain in round 3, this may have lower personal relevance to, for example, patients who are studying or retired. Thus, further work is needed to refine this outcome domain such that it is more broadly relevant to all kidney transplant populations, irrespective of age, gender, and socio-economic factors.

Compared with other Delphi surveys used to establish core outcomes, our sample size is large with a broad representation of different stakeholders across 79 countries and had a high response rate of $77 \%$ by round $3(46,47)$. Our findings also included qualitative data to provide further insights into the meaning, reasons and interpretations of the outcomes by participants. However, there are some potential limitations. For technical reasons and feasibility, we administered the survey in English-language, which precluded a larger representation of patients and caregivers from non-English speaking countries with different health systems. Therefore, the generalizability to non-English speaking countries may be 
uncertain. Also, the survey could only be accessed online to facilitate broader dissemination and minimize data entry errors, which limited participation to those with internet access and computer literacy.

Core outcomes should be reported in all trials in kidney transplantation because they are relevant and important to patients and clinicians. Patients and clinicians want to know the effect of an intervention on outcomes they regard as critically important irrespective of whether the intervention makes a difference. Researchers are not required to use a core outcome as a primary endpoint to estimate the sample size required to adequately power a study. Also, researchers may add other outcomes based on other considerations including responsiveness to an intervention and feasibility.

Our international SONG-Tx Delphi survey has achieved clear consensus on high priority outcome domains to report in all trials involving kidney transplant recipients. These pertained to preservation of the graft and common life-threatening medical complications cancer, infection, and cardiovascular disease. However, there is increasing emphasis on explicitly including patient-reported outcomes, which may be inherent in graft survival and clinical complications. Further stakeholder engagement through consensus workshops is needed, to discuss the inclusion of patient-reported outcomes, and to ascertain appropriate, feasible, and acceptable approaches for establishing core outcome domains in kidney transplantation. We will present the findings from the Delphi survey at SONG-Tx consensus workshops for review and discussion by patients, caregivers, clinicians, researchers, and policy makers. Once the core outcome domains are established, subsequent work to identify core outcome measures will ensue, which may be informed from complementary initiatives such as the Clinical Data Interchange Standards Consortium (CDISC). CDISC recently published the Kidney Transplant Therapeutic Area User Guide (TAUG-KT) to facilitate standardized reporting of data. (50)

Improving the consistency and relevance of trial endpoints in kidney transplantation can ultimately empower patients and clinicians to make critical treatment decisions based on outcomes that explicitly matter to them.

\section{Supplementary Material}

Refer to Web version on PubMed Central for supplementary material.

\section{Acknowledgments}

We thank all the participants who were participated on the SONG-Tx Delphi Panel. We are very grateful to all the collaborating organizations for helping to invite patients, caregivers and health professionals to participate.

Funding: This project is supported by a National Health and Medical Research Council Project Grant (1128564) and Program Grant (1092597). AT is supported by a NHMRC Career Development Fellowship (1106716). JS is supported by a National Institutes for Health (NIH) K23 Career Development Grant (DK103972).

\section{Authors' specific contributions:}

BS participated in the research design, data collection, data analysis, and drafted the manuscript. 
AT participated in the research design, data collection, data analysis, and drafted the manuscript.

KEM participated in the research design, data collection, data analysis, and drafted the manuscript.

JRC participated in the research design, data analysis, and provided intellectual input on the manuscript and contributed to manuscript writing.

AW participated in the research design, data analysis, and provided intellectual input on the manuscript and contributed to manuscript writing.

DR participated in the research design, data analysis, and provided intellectual input on the manuscript and contributed to manuscript writing.

GW participated in the research design, data analysis, and provided intellectual input on the manuscript and contributed to manuscript writing.

JG participated in the research design, data analysis, and provided intellectual input on the manuscript and contributed to manuscript writing.

KB participated in the research design, data analysis, and provided intellectual input on the manuscript and contributed to manuscript writing.

LR participated in the research design, data analysis, and provided intellectual input on the manuscript and contributed to manuscript writing.

LM participated in the research design, data analysis, and provided intellectual input on the manuscript and contributed to manuscript writing.

MAJ participated in the research design, data analysis, and provided intellectual input on the manuscript and contributed to manuscript writing.

PR participated in the research design, data analysis, and provided intellectual input on the manuscript and contributed to manuscript writing.

TP participated in the research design, data analysis, and provided intellectual input on the manuscript and contributed to manuscript writing.

CSH participated in the research design, and provided intellectual input on the manuscript and contributed to manuscript writing.

DO participated in the research design, and provided intellectual input on the manuscript and contributed to manuscript writing.

HT participated in the research design, and provided intellectual input on the manuscript and contributed to manuscript writing.

JMH participated in the research design, and provided intellectual input on the manuscript and contributed to manuscript writing.

Transplantation. Author manuscript; available in PMC 2018 August 01. 
JIS participated in the research design, and provided intellectual input on the manuscript and contributed to manuscript writing.

JK participated in the research design, and provided intellectual input on the manuscript and contributed to manuscript writing.

JDS participated in the research design, and provided intellectual input on the manuscript and contributed to manuscript writing.

$\mathrm{KH}$ participated in the research design, and provided intellectual input on the manuscript and contributed to manuscript writing.

MH participated in the research design, and provided intellectual input on the manuscript and contributed to manuscript writing.

NC participated in the research design, and provided intellectual input on the manuscript and contributed to manuscript writing.

NE participated in the research design, data analysis, and provided intellectual input on the manuscript and contributed to manuscript writing.

PM participated in the research design, data analysis, and provided intellectual input on the manuscript and contributed to manuscript writing.

RO participated in the research design, data analysis, and provided intellectual input on the manuscript and contributed to manuscript writing.

SF participated in the research design, data analysis, and provided intellectual input on the manuscript and contributed to manuscript writing.

SJ participated in the research design, data analysis, and provided intellectual input on the manuscript and contributed to manuscript writing.

SK participated in the research design, data analysis, and provided intellectual input on the manuscript and contributed to manuscript writing.

SM participated in the research design, data analysis, and provided intellectual input on the manuscript and contributed to manuscript writing.

SPM participated in the research design, and provided intellectual input on the manuscript and contributed to manuscript writing.

SC participated in the research design, and provided intellectual input on the manuscript and contributed to manuscript writing.

TR participated in the research design, and provided intellectual input on the manuscript and contributed to manuscript writing.

JCC participated in the research design, data collection, data analysis, and drafted the manuscript.

Transplantation. Author manuscript; available in PMC 2018 August 01. 


\section{Abbreviations}

\section{SONG-Tx Standardized Outcomes in Nephrology - kidney transplantation}

\section{References}

1. Stegall MD, Gaston RS, Cosio FG, Matas A. Through a glass darkly: seeking clarity in preventing late kidney transplant failure. J Am Soc Nephrol. 2015; 26(1):20-9. [PubMed: 25097209]

2. Shapiro R, Basu A, Tan H, et al. Kidney transplantation under minimal immunosuppression after pretransplant lymphoid depletion with thymoglobulin or campath. J Am Coll Surg. 2005; 200(4): 505-A61. [PubMed: 15804464]

3. Lodhi SA, Meier-Kriesche H-U. Kidney allograft survival: the long and short of it. Nephrol Dial Transplant. 2011; 26(1):15-7. [PubMed: 21177522]

4. Nankivell BJ, Kuypers DRJ. Diagnosis and prevention of chronic kidney allograft loss. Lancet. 2011; 378(9800):1428-37. [PubMed: 22000139]

5. Matas AJ, Gillingham KJ, Humar A, et al. 2202 kidney transplant recipients with 10 years of graft function: what happens next? Am J Transplant. 2008; 8(11):2410-9. [PubMed: 18925907]

6. De Geest S, Moons P. The patient's appraisal of side-effects: the blind spot in quality-of-life assessments in transplant recipients. Nephrol Dial Transplant. 2000; 15(4):457-9. [PubMed: 10727538]

7. Ioannidis JPA, Greenland S, Hlatky MA, et al. Increasing value and reducing waste in research design, conduct, and analysis. Lancet. 2014; 383(9912):166-75. [PubMed: 24411645]

8. Masson P, Duthie FA, Ruster LP, et al. Consistency and completeness of reported outcomes in randomized trials of primary immunosuppression in kidney transplantation. Am J Transplant. 2013; 13(11):2892-901. [PubMed: 24102933]

9. Hussain S, Knight SR. Quality and consistency of outcome reporting in clinical trials of immunosuppression in renal transplantation. Clin Transplant. 2016; 30(11):1440-8. [PubMed: 27582408]

10. Howell M, Wong G, Turner RM, Tan HT, Tong A, Craig JC, et al. The consistency and reporting of quality-of-life outcomes in trials of immunosuppressive agents in kidney transplantation: a systematic review and meta-analysis. Am J Kidney Dis. 2016; 67(5):762-74. [PubMed: 26724168]

11. Chalmers I, Bracken MB, Djulbegovic B, et al. How to increase value and reduce waste when research priorities are set. Lancet. 2014; 383(9912):156-65. [PubMed: 24411644]

12. Williamson PR, Altman DG, Blazeby JM, et al. Developing core outcome sets for clinical trials: issues to consider. Trials. 2012; 13:132. [PubMed: 22867278]

13. Tong A, Budde K, Gill J, et al. Standardized outcomes in nephrology-transplantation: a global initiative to develop a core outcome set for trials in kidney transplantation. Transplant Direct. 2016; 2(6):e79. [PubMed: 27500269]

14. Evangelidis N, Tong A, Manns B, et al. Developing a set of core outcomes for trials in hemodialysis: an international Delphi survey. Am J Kidney Dis. 2017 S0272-6386(17)30035-5.

15. Van 't Hooft J. A core outcome set for evaluation of interventions to prevent preterm birth: summary for CROWN. BJOG. 2016; 123(Suppl 3):107. [PubMed: 27627610]

16. McNair AGK, Whistance RN, Forsythe RO, et al. Core outcomes for colorectal cancer surgery: a consensus study. PLoS Med. 2016; 13(8):e1002071. [PubMed: 27505051]

17. Karas J, Ashkenazi S, Guarino A, et al. A core outcome set for clinical trials in acute diarrhoea. Arch Dis Child. 2015; 100(4):359-63. [PubMed: 25414251]

18. Hopkins J, Howes N, Chalmers K, et al. What are important outcomes of bariatric surgery? An indepth analysis to inform the development of a core outcome set and a comparison between the views of surgeons and other health professionals (the BARIACT study). Lancet. 2015; 385(Suppl 1):S43.

19. Jones J, Hunter D. Consensus methods for medical and health services research. BMJ. 1995; 311(7001):376-80. [PubMed: 7640549] 
20. Murphy MK, Black NA, Lamping DL, et al. Consensus development methods, and their use in clinical guideline development. Health Technol Assess. 1998; 2(3):i-iv. 1-88.

21. Howell M, Tong A, Wong G, Craig JC, Howard K. Important outcomes for kidney transplant recipients: a nominal group and qualitative study. Am J Kidney Dis. 2012; 60(2):186-96. [PubMed: 22578839]

22. Howell M, Wong G, Turner RM, et al. The consistency and reporting of quality-of-life outcomes in trials of immunosuppressive agents in kidney transplantation: a systematic review and metaanalysis. Am J Kidney Dis. 2016; 67(5):762-74. [PubMed: 26724168]

23. Dobbels F, Wong S, Min Y, Sam J, Kalsekar A. Beneficial effect of belatacept on health-related quality of life and perceived side effects: results from the BENEFIT and BENEFIT-EXT trials. Transplantation. 2014; 98(9):960-8. [PubMed: 24831918]

24. LimeSurvey Project Team/Carsten Schmitz. LimeSurvey: An Open Source survey tool. http:// www.limesurvey.org. Published 2015

25. Schunemann, H., Brozek, J., Oxman, A. GRADE Handbook for grading quality of evidence and strength of recommendation. http://gdt.guidelinedevelopment.org/app/handbook/handbook.html. Published 2009

26. Krosnick JA. Survey research. Annu Rev Psychol. 1999; 50:537-67. [PubMed: 15012463]

27. American Society of Nephrology. American Society of Nephrology Renal Research Report. J Am Soc Nephrol. 2005; 16(7):1886-903. [PubMed: 15888557]

28. Tong A, Sainsbury P, Carter SM, et al. Patients' priorities for health research: focus group study of patients with chronic kidney disease. Nephrol Dial Transplant. 2008; 23(10):3206-14. [PubMed: 18445638]

29. Tong A, Crowe S, Chando S, et al. Research priorities in CKD: report of a national workshop conducted in australia. Am J Kidney Dis. 2015; 66(2):212-22. [PubMed: 25943716]

30. Vajdic CM, McDonald SP, McCredie MRE, et al. Cancer incidence before and after kidney transplantation. JAMA. 2006; 296(23):2823-31. [PubMed: 17179459]

31. Jardine AG, Gaston RS, Fellstrom BC, Holdaas H. Prevention of cardiovascular disease in adult recipients of kidney transplants. The Lancet. 2011; 378(9800):1419-27.

32. Chapman JR. The consequences of successful transplantation. The Lancet. 2011; 378(9800):13579.

33. Sharif A, Hecking M, de Vries APJ, et al. Proceedings from an international consensus meeting on posttransplantation diabetes mellitus: recommendations and future directions. Am J Transplant. 2014; 14(9):1992-2000. [PubMed: 25307034]

34. Schipper K, Abma TA. Coping, family and mastery: top priorities for social science research by patients with chronic kidney disease. Nephrol Dial Transplant. 2011; 26(10):3189-95. [PubMed: 21378151]

35. McAlister FA, van Diepen S, Padwal RS, Johnson JA, Majumdar SR. How evidence-based are the recommendations in evidence-based guidelines? PLoS Med. 2007; 4(8):e250. [PubMed: 17683197]

36. Doran CM, Ling R, Byrnes J, et al. Benefit cost analysis of three skin cancer public education mass-media campaigns implemented in New South Wales, Australia. PloS One. 2016; 11(1):e0147665. [PubMed: 26824695]

37. Hingle MD, Snyder AL, McKenzie NE, et al. Effects of a short messaging service-based skin cancer prevention campaign in adolescents. Am J Prev Med. 2014; 47(5):617-23. [PubMed: 25053602]

38. Schulz EJ. Sun education in South Africa. Clin Dermatol. 1998; 16(4):531-3. [PubMed: 9699072]

39. Freiman A, Yu J, Loutfi A, Wang B. Impact of melanoma diagnosis on sun-awareness and protection: efficacy of education campaigns in a high-risk population. J Cutan Med Surg. 2004 8(5):303-9. [PubMed: 15868284]

40. Veater NL, East L. Exploring depression amongst kidney transplant recipients: a literature review. J Ren Care. 2016; 42(3):172-84. [PubMed: 27220908]

41. Müller HH, Englbrecht M, Wiesener MS, et al. Depression, anxiety, resilience and coping pre and post kidney transplantation - initial findings from the Psychiatric Impairments in Kidney Transplantation (PI-KT)-Study. PloS One. 2015; 10(11):e0140706. [PubMed: 26559531] 
42. Griva K, Thompson D, Jayasena D, Davenport A, Harrison M, Newman SP. Cognitive functioning pre- to post-kidney transplantation-a prospective study. Nephrol Dial Transplant. 2006; 21(11): 3275-82. [PubMed: 16861731]

43. Singh P, Ng Y-H, Unruh M. Kidney Transplantation Among the Elderly: Challenges and opportunities to improve outcomes. Adv Chronic Kidney Dis. 2016; 23(1):44-50. [PubMed: 26709062]

44. Van Sandwijk MS, Ten Berge IJM, Majoie CBLM, et al. Cognitive changes in chronic kidney disease and after transplantation. Transplantation. 2016; 100(4):734-42. [PubMed: 26479287]

45. Tamura MK, Yaffe K. Dementia and cognitive impairment in ESRD: diagnostic and therapeutic strategies. Kidney Int. 2011; 79(1):14-22. [PubMed: 20861818]

46. Kostro JZ, Hellmann A, Kobiela J, et al. Quality of life after kidney transplantation: a prospective study. Transplant Proc. 2016; 48(1):50-4. [PubMed: 26915842]

47. Czyżewski L, Sańko-Resmer J, Wyzgał J, Kurowski A. Assessment of health-related quality of life of patients after kidney transplantation in comparison with hemodialysis and peritoneal dialysis. Ann Transplant. 2014; 19:576-85. [PubMed: 25382249]

48. Rahimi K, Malhotra A, Banning AP, Jenkinson C. Outcome selection and role of patient reported outcomes in contemporary cardiovascular trials: systematic review. BMJ. 2010; 341:c5707. [PubMed: 21041324]

49. U.S. Department of Health and Human Services FDA Center for Drug Evaluation and Research, U.S. Department of Health and Human Services FDA Center for Biologics Evaluation and Research, U.S. Department of Health and Human Services FDA Center for Devices and Radiological Health. Guidance for industry; patient-reported outcome measures: use in medical product development to support labeling claims: draft guidance. Health Qual Life Outcomes. 2006; 4:79. [PubMed: 17034633]

50. Clinical Data Interchange Standards Consortium (CDISC). Kidney Transplant Therapeutic Area User Guide (TAUG-KT) Version 1.0. 2016. https://www.cdisc.org/standards/therapeutic-areas/ kidney-transplant/kidney-transplant-therapeutic-area-user-guide-v10. Published December 31 2016. Accessed 15th February 2017 


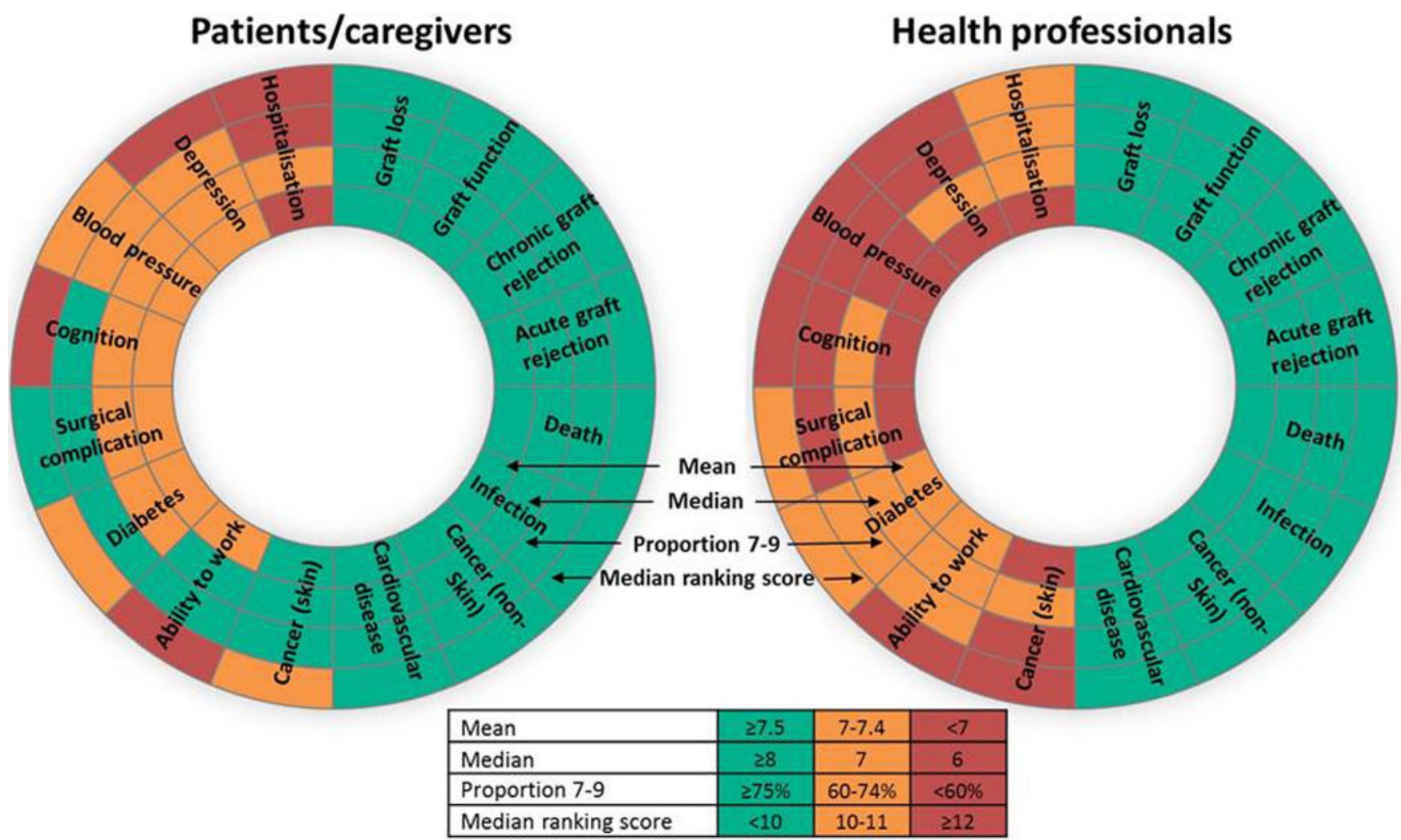

Figure 1. Consensus criteria and outcome domains

Outcomes included in the potential core outcome set met at least two of the following criteria: mean score of greater than or equal to 7.5 ; mean score greater than or equal to 8 ; proportion of participants rating the outcome 7 to 9 (critically important) is greater than or equal to 75 , and the median is less than 10 based on the forced ranking question. 


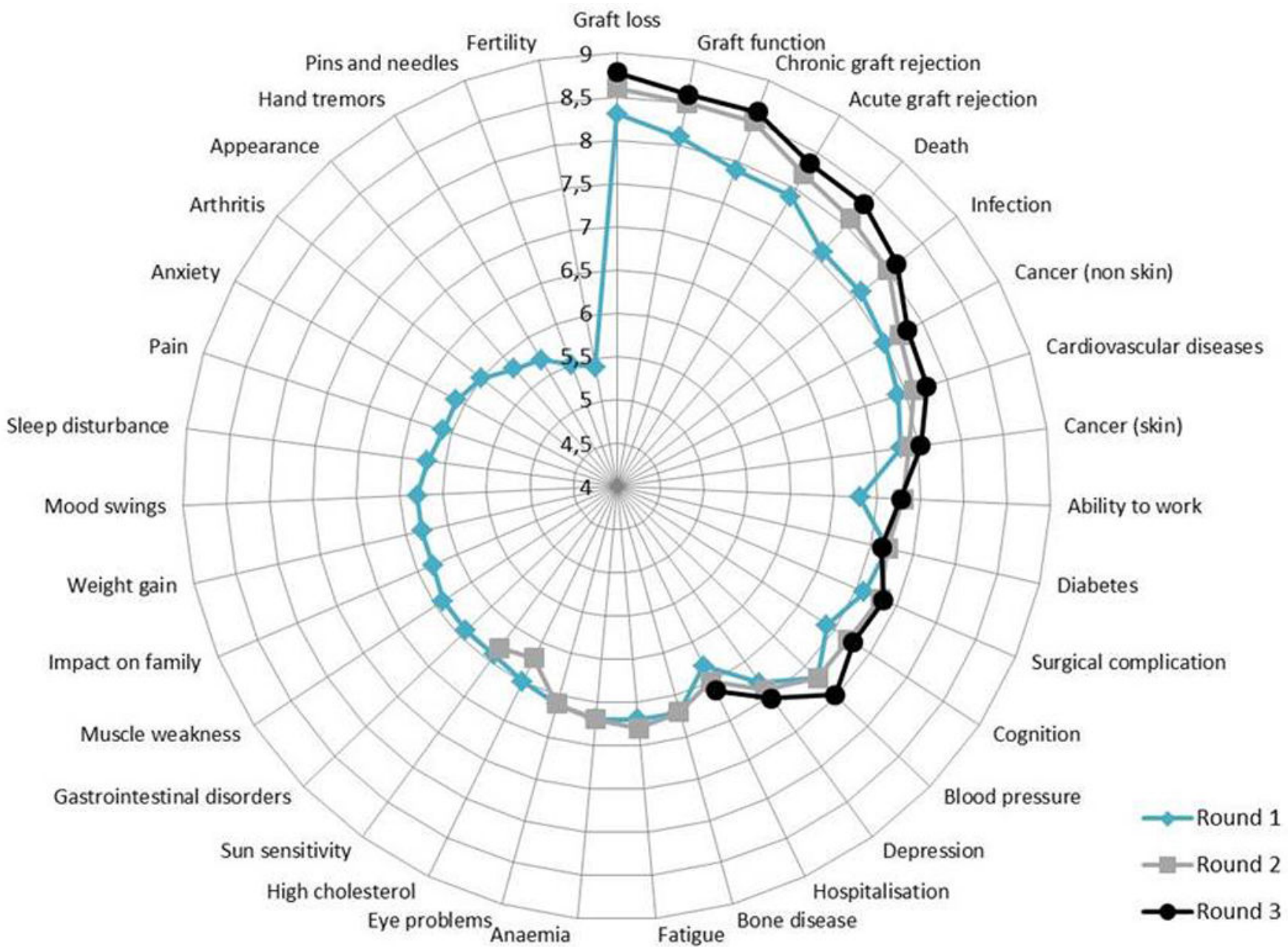

Figure 2.

Mean scores of patients/caregivers in rounds 1-3 


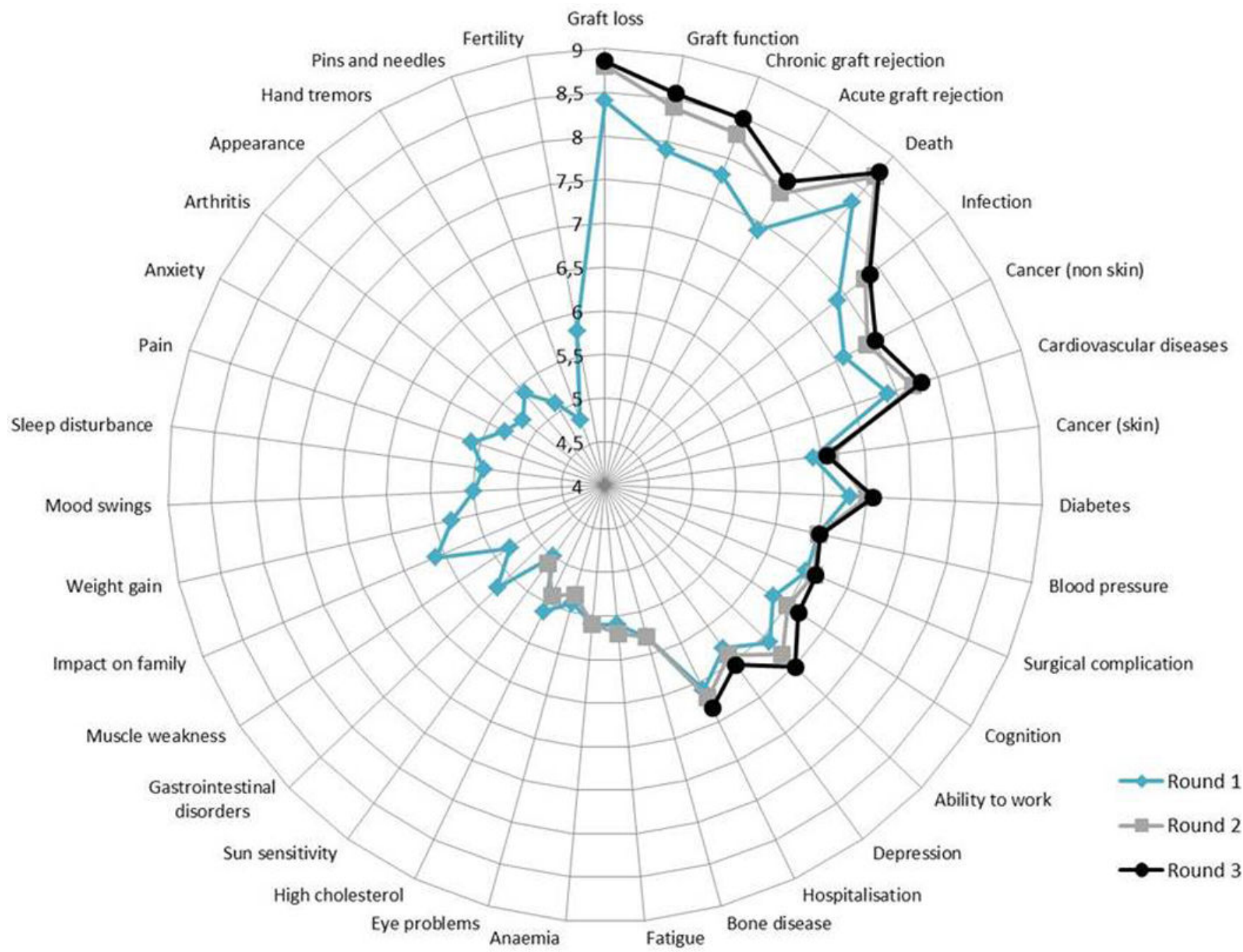

Figure 3.

Mean scores of health professionals in rounds 1-3 


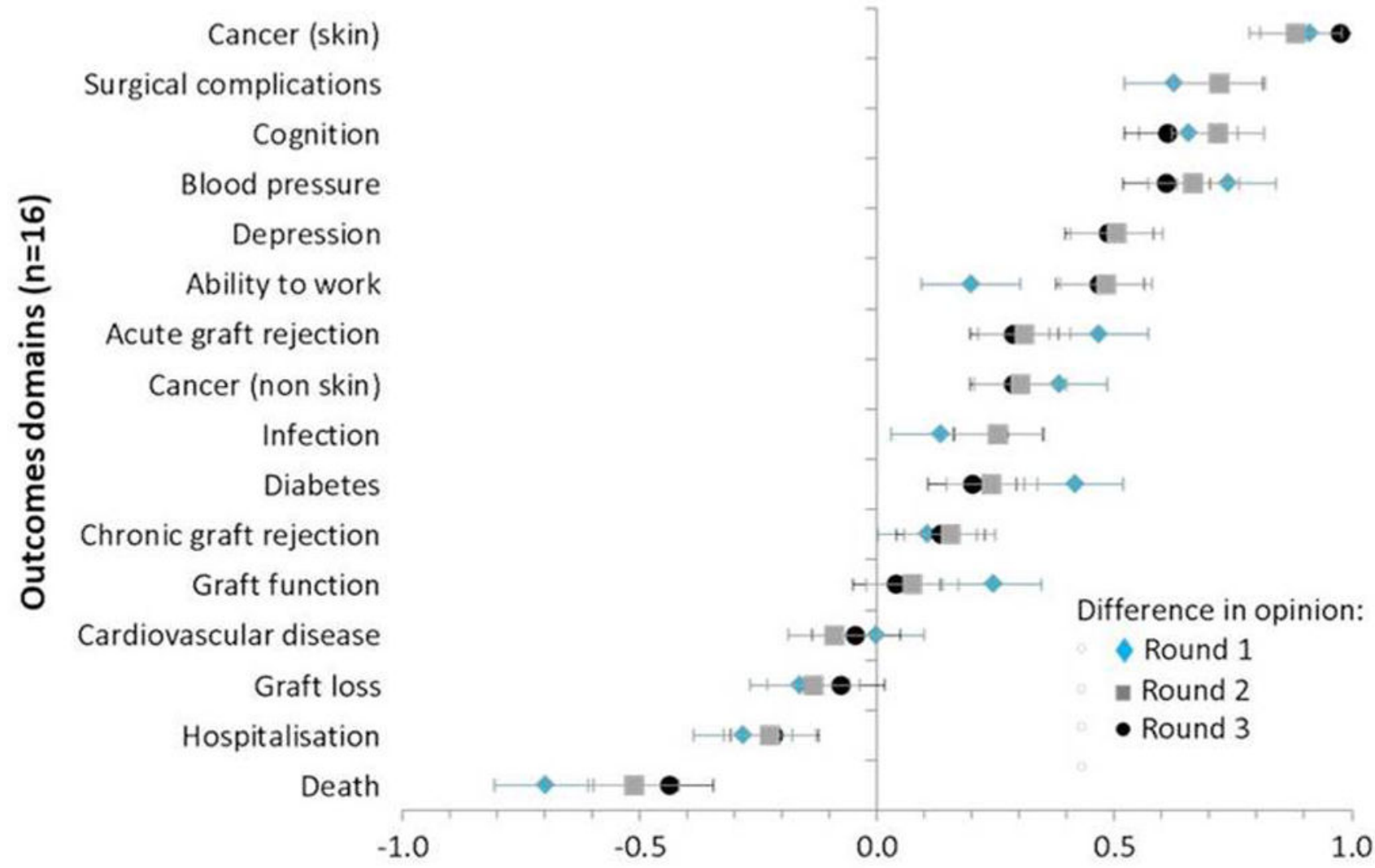

Favoured by health professionals

Favoured by patients

\section{DIFFERENCE IN OPINION, round 1, 2 and 3 (difference in the mean scores)}

Figure 4. Differences in mean scores between patients/caregivers and health professionals in rounds 1-3

*The top 8 outcome domains for both stakeholder groups that met at least two of the following criteria: mean score of greater than or equal to 7.5 ; mean score greater than or equal to 8; proportion of participants rating the outcome 7 to 9 (critically important) is greater than or equal to 75 , and the median is less than 10 based on the forced ranking question. 


\section{Table 1}

Characteristics of patients/caregivers

\begin{tabular}{|c|c|c|c|}
\hline Characteristic & $\begin{array}{l}\text { Round 1, n (\%) } \\
461 \text { participants }\end{array}$ & $\begin{array}{l}\text { Round 2, n (\%) } \\
387 \text { participants }\end{array}$ & $\begin{array}{l}\text { Round 3, n (\%) } \\
360 \text { participants }\end{array}$ \\
\hline \multicolumn{4}{|l|}{ Participant type ${ }^{a}$} \\
\hline Patient & $381(82.3)$ & $325(83.5)$ & $300(82.9)$ \\
\hline Caregiver/family member & $35(7.6)$ & $28(7.2)$ & $27(7.5)$ \\
\hline Kidney donor & $47(10.1)$ & $36(9.3)$ & $35(9.6)$ \\
\hline \multicolumn{4}{|l|}{ Gender } \\
\hline Male & $211(45.8)$ & $182(47.0)$ & $173(48.1)$ \\
\hline Female & $250(54.2)$ & $205(53.0)$ & $187(51.9)$ \\
\hline \multicolumn{4}{|l|}{ Age group (years) } \\
\hline $18-40$ & $71(15.4)$ & $52(13.4)$ & $48(13.4)$ \\
\hline $41-50$ & $119(25.8)$ & $95(24.5)$ & $86(23.9)$ \\
\hline $51-60$ & $138(29.9)$ & $120(31.0)$ & $111(30.8)$ \\
\hline $61-70$ & $113(24.5)$ & $102(26.4)$ & $97(26.9)$ \\
\hline$\geq 71$ & $20(4.3)$ & $18(4.7)$ & $18(5.0)$ \\
\hline \multicolumn{4}{|l|}{ Marital status } \\
\hline Single & $70(15.2)$ & $62(16.0)$ & $56(15.6)$ \\
\hline Partner/de-facto & $38(8.3)$ & $31(8.0)$ & $27(7.5)$ \\
\hline Married & 307 (66.6) & $257(66.4)$ & $241(66.9)$ \\
\hline Divorced/separated/widowed & $46(10.0)$ & $34(9.5)$ & $36(10.0)$ \\
\hline \multicolumn{4}{|l|}{ Number of children } \\
\hline 0 & $157(34.1)$ & $137(35.4)$ & $130(36.1)$ \\
\hline $1-2$ & $212(46.0)$ & $172(44.4)$ & $162(45.0)$ \\
\hline$>3$ & $92(20.0)$ & $78(20.2)$ & $69(18.9)$ \\
\hline \multicolumn{4}{|l|}{ Employment status } \\
\hline Employed & $261(56.6)$ & $210(54.3)$ & $192(53.3)$ \\
\hline Unemployed & $40(8.7)$ & $34(8.8)$ & $30(8.3)$ \\
\hline Retired & $110(23.9)$ & $101(26.1)$ & $98(27.2)$ \\
\hline Student or other & $50(10.9)$ & $43(10.7)$ & $40(11.1)$ \\
\hline \multicolumn{4}{|l|}{ Education } \\
\hline Did not complete high school & $91(19.7)$ & $77(19.9)$ & $70(19.4)$ \\
\hline High school graduate & $55(11.9)$ & $43(11.1)$ & $40(11.1)$ \\
\hline Professional certificate & 109 (23.6) & $89(23.0)$ & $86(23.9)$ \\
\hline Undergraduate degree & $131(28.4)$ & $110(28.4)$ & $101(28.1)$ \\
\hline
\end{tabular}




\begin{tabular}{|c|c|c|c|}
\hline Characteristic & $\begin{array}{l}\text { Round 1, n (\%) } \\
461 \text { participants }\end{array}$ & $\begin{array}{l}\text { Round 2, n (\%) } \\
387 \text { participants }\end{array}$ & $\begin{array}{l}\text { Round 3, n (\%) } \\
360 \text { participants }\end{array}$ \\
\hline Postgraduate degree & $75(16.3)$ & $68(17.6)$ & $63(17.5)$ \\
\hline \multicolumn{4}{|l|}{ Current type of treatment } \\
\hline Kidney transplant from a deceased donor & $189(49.6)$ & $168(51.7)$ & $160(53.3)$ \\
\hline Kidney transplant from a living donor & $124(32.5)$ & $97(29.8)$ & $91(30.3)$ \\
\hline Hemodialysis & $39(10.2)$ & $34(10.5)$ & $28(9.3)$ \\
\hline Peritoneal dialysis & $7(1.8)$ & $6(1.8)$ & $4(1.3)$ \\
\hline No renal replacement therapy & $22(5.8)$ & $20(6.2)$ & $17(5.7)$ \\
\hline \multicolumn{4}{|l|}{ Years on transplantation } \\
\hline 0 & $122(26.5)$ & $99(25.6)$ & $88(24.4)$ \\
\hline$<1$ & $37(8.0)$ & $32(8.3)$ & $29(8.1)$ \\
\hline $1-5$ & $105(22.8)$ & $90(23.2)$ & $86(23.9)$ \\
\hline $6-10$ & $68(14.7)$ & $60(15.5)$ & $56(15.5)$ \\
\hline$>10$ & $129(28.0)$ & $106(27.4)$ & $101(28.1)$ \\
\hline \multicolumn{4}{|l|}{ Number of kidney transplants } \\
\hline 0 & $122(26.5)$ & 99 (25.6) & $88(24.4)$ \\
\hline 1 & $283(61.4)$ & $242(62.5)$ & $228(63.3)$ \\
\hline 2 & $41(8.9)$ & $35(9.1)$ & $33(9.2)$ \\
\hline$>3$ & $15(3.2)$ & $11(2.8)$ & $11(3.1)$ \\
\hline \multicolumn{4}{|l|}{ Cause of kidney disease } \\
\hline Diabetes & $20(5.2)$ & $19(5.8)$ & $19(6.2)$ \\
\hline Glomerulonephritis & $95(24.6)$ & $79(23.9)$ & $75(24.6)$ \\
\hline Polycystic kidney disease or inherited & $102(26.4)$ & $94(28.5)$ & $85(27.9)$ \\
\hline Other & $129(33.4)$ & $105(31.8)$ & $99(32.5)$ \\
\hline Unknown & $40(10.4)$ & $33(10.0)$ & $27(8.9)$ \\
\hline \multicolumn{4}{|l|}{ Country } \\
\hline Australia & $198(42.9)$ & $176(45.5)$ & $167(46.4)$ \\
\hline United Kingdom & $70(15.2)$ & $59(15.2)$ & $55(15.3)$ \\
\hline New Zealand & $32(6.9)$ & $27(7.0)$ & $26(7.2)$ \\
\hline United States & $38(8.2)$ & $27(7.0)$ & $23(6.4)$ \\
\hline Other ${ }^{*}$ & $123(26.7)$ & $98(25.3)$ & $89(24.7)$ \\
\hline
\end{tabular}

${ }^{a}$ Some have multiple roles;

*

Other includes 22 countries: South Africa, Canada, Denmark, Ireland, China, Netherlands, Czech Republic, Greece, Spain, Austria, Belgium, Brazil, Cyprus, Finland, Georgia, Germany, Libya, Luxembourg, Poland, Slovenia, Turkey and Uruguay. NB. Percentages may not equal $100 \%$ due to rounding or duplicate categories. Respondents who do not complete round 2 cannot complete round 3. 


\section{Table 2}

Characteristics of health professionals

\begin{tabular}{|c|c|c|c|}
\hline Characteristic & $\begin{array}{l}\text { Round 1, n (\%) } \\
557 \text { participants }\end{array}$ & $\begin{array}{l}\text { Round 2, n (\%) } \\
457 \text { participants }\end{array}$ & $\begin{array}{l}\text { Round 3, n (\%) } \\
419 \text { participants }\end{array}$ \\
\hline \multicolumn{4}{|l|}{ Participant type ${ }^{a}$} \\
\hline Nephrologist & $371(58.3)$ & $301(56.4)$ & $281(56.7)$ \\
\hline Surgeon & $33(5.2)$ & $24(4.5)$ & $22(4.4)$ \\
\hline Nurse & $66(10.4)$ & $59(11.0)$ & $49(9.9)$ \\
\hline Psychiatrist & $2(0.3)$ & $2(0.4)$ & $2(0.4)$ \\
\hline Psychologist & $2(0.3)$ & $2(0.4)$ & $2(0.4)$ \\
\hline Social Worker & $6(1.0)$ & $6(1.1)$ & $5(1.0)$ \\
\hline Dietician & $7(1.1)$ & $7(1.3)$ & $6(1.2)$ \\
\hline Researcher & $75(11.8)$ & $69(12.9)$ & $61(12.3)$ \\
\hline Pharmacist & $18(2.9)$ & $14(2.6)$ & $10(2.0)$ \\
\hline Policy maker & $12(1.9)$ & $11(2.1)$ & $10(2.0)$ \\
\hline Industry & $5(0.8)$ & $4(0.7)$ & $2(0.4)$ \\
\hline Others & $40(6.3)$ & $35(6.6)$ & $26(5.2)$ \\
\hline \multicolumn{4}{|l|}{ Gender } \\
\hline Male & $308(55.3)$ & $250(54.7)$ & $233(55.6)$ \\
\hline Female & $249(44.7)$ & $207(45.3)$ & $186(44.4)$ \\
\hline \multicolumn{4}{|l|}{ Age group (years) } \\
\hline $18-40$ & $166(29.8)$ & $137(30.0)$ & $116(27.7)$ \\
\hline $41-50$ & $177(31.8)$ & $142(31.1)$ & $132(31.5)$ \\
\hline $51-60$ & $156(28.0)$ & $130(28.4)$ & $126(30.1)$ \\
\hline $61-70$ & $52(9.3)$ & $43(9.4)$ & $40(9.5)$ \\
\hline$\geq 71$ & $6(1.1)$ & $5(1.1)$ & $5(1.2)$ \\
\hline
\end{tabular}

Experience in transplantation (years)

\begin{tabular}{llll}
\hline$\leq 10$ & $207(37.2)$ & $159(34.8)$ & $134(32.0)$ \\
$11-20$ & $183(32.9)$ & $156(34.1)$ & $150(35.8)$ \\
$\geq 21$ & $167(30.0)$ & $142(31.1)$ & $135(32.2)$ \\
\hline No. of transplantation trials as investigators & & & \\
\hline 0 & $250(44.9)$ & $207(45.3)$ & $185(44.2)$ \\
$1-5$ & $180(32.3)$ & $151(33.0)$ & $140(33.4)$ \\
$6-10$ & $58(10.4)$ & $46(10.1)$ & $42(10.0)$ \\
$\geq 11$ & $69(12.4)$ & $53(11.6)$ & $52(12.4)$ \\
\hline Specific role in kidney transplant research & & & \\
\hline Government, policy making & & & \\
\end{tabular}




\begin{tabular}{lccc}
\hline Characteristic & $\begin{array}{c}\text { Round 1, }(\%) \\
\text { 557 participants }\end{array}$ & $\begin{array}{c}\text { Round 2, } \mathbf{n}(\%) \\
\text { 457 participants }\end{array}$ & $\begin{array}{c}\text { Round 3, }(\%) \\
\text { 419 participants }\end{array}$ \\
\hline Clinical practice guidelines & $226(47.0)$ & $185(463)$ & $178(46.7)$ \\
Funding (grant reviewer, panel) & $126(26.2)$ & $106(26.5)$ & $100(26.2)$. \\
Other & $35(7.3)$ & $29(7.3)$ & $25(6.6)$ \\
\hline Country ${ }^{*}$ & & & \\
\hline Australia & & & $54(12.9)$ \\
United states & $70(12.6)$ & $58(12.7)$ & $46(11.0)$ \\
Canada & $66(11.8)$ & $52(11.4)$ & $40(9.5)$ \\
New Zealand & $53(9.5)$ & $44(9.6)$ & $37(8.8)$ \\
United Kingdom & $39(7.0)$ & $38(8.3)$ & $30(7.2)$ \\
France & $36(6.5)$ & $31(6.8)$ & $25(6.0)$ \\
Spain & $34(6.1)$ & $27(5.9)$ & $17(4.1)$ \\
China and Hong Kong & $23(4.1)$ & $19(4.2)$ & $12(2.9)$ \\
Italy & $19(3.4)$ & $14(3.1)$ & $7(1.7)$ \\
Netherland & $13(2.3)$ & $9(2.0)$ & $8(1.9)$ \\
Brazil & $12(2.2)$ & $9(2.0)$ & $9(2.1)$ \\
Other & $12(2.2)$ & $11(2.4)$ & $134(32.0)$ \\
\hline & $180(32.3)$ & $145(31.7)$ & \\
\hline
\end{tabular}

${ }^{a}$ Some have multiple roles.

*

* Other includes 64 countries: Austria, Belgium, Germany, Portugal, India, Romania, Egypt, Greece, Saudi Arabia, Finland, Mexico, Switzerland, Argentina, Colombia, Sweden, Japan, Montenegro, Poland, Serbia, Thailand, Vietnam, Cameroon, Chile, Croatia, Denmark, Kosovo, Lithuania, Nigeria, Norway, Oman, Singapore, Slovakia, Slovenia, South Africa, Turkey, Ukraine, United Arab Emirates, Algeria, Bangladesh, Bolivia, Bulgaria, Cape Verde, Chad, Czech Republic, Ecuador, Guatemala, Honduras, Hungary, Iran, Ireland, Jordan, Kenya, Korea South, Luxembourg, Macedonia, Malaysia, Myanmar, Pakistan, Panama, Philippines, Sri Lanka, Taiwan, Trinidad \& Tobago and Venezuela. NB. Percentages may not equal $100 \%$ due to rounding or duplicate categories. 


\section{Table 3}

\section{Selected illustrative quotations}

\begin{tabular}{l}
\hline Theme \\
\hline Capacity to control and inevitability \\
Patients/caregivers
\end{tabular}

Skin cancer is an acceptable risk for having a functional graft. With proper surveillance by the patient/carer it can be treated effectively. (cancer - skin)

This is not necessarily life threatening and can be treated. (high cholesterol)

Patient should be aware and act accordingly, if they don't it's nobody's doing but their own. (sun sensitivity)

I determine my outcome and health every day. If I don't look after myself, I must be able to cope with what happens then. I might not suffer, my family and friends are the ones who suffer. (graft loss)

Death is inevitable at some stage for all us however we need to be realistic that a transplant is not a cure for kidney disease, it is a preferable treatment to dialysis and gives one quality of life for the duration that the graft lasts. I believe a lot depends on how you look after yourself posttransplant. (death)

I agree with the comment that it's a silent killer but I have rated this 1 . I have my own BP machine and I keep an eye on it. Again, it comes back to what I eat and my exercise. It is my responsibility to check my BP. Making yourself knowledgeable about your health is important. (blood pressure)

It is an important problem but can be treated successfully. (acute graft rejection)

Important but not critical. If you're going to die you're going to die and if you've had a transplant you've at least lived longer, even if you're on dialysis every night you are still alive, be grateful. (death)

I've changed my views on this as most skin cancers can be removed fairly quickly removed before they spread. (cancer-skin)

\section{Health professionals}

Known and generally control pretty good these days. (blood pressure)

Clearly important but largely acute rejection has been shown to be generally reversible and treatable. Less important area for research in my opinion. (acute graft rejection)

Clearly of critical importance in the balance with rejection. However most infections are rather easy to treat or preventable, causing less problems nowadays so it is not as critical anymore. But clearly infection may directly cause graft loss and death, and treatment may be costly, require hospitalizations and have side effects. (infection)

I changed my answer. It's critical, but experienced surgeons make miracles happen. (surgical complications)

\section{Personal relevance}

\section{Patients/caregivers}

Depends on age and circumstances but is an indication that life is as normal as possible. (ability to work)

I have moved this up because although not something I am particularly dealing with, I can see that it would be massive for many patients dealing with the transition. (depression)

For patients of working age, this must be the single most important outcome measure, since it is also a surrogate indicator of the success of all other outcome measures. (ability to work)

I'm retired, even through all the years I was working, I never found my health restricting work. It's very much a state of mind. I'm keeping my score of 1. (ability to work)

A very personal perspective based on personal experience having not experienced most of outcomes but hopefully sympathetic to those who might have. (general)

\section{Health professionals}

Particularly for fertile women, this is critical. (fertility)

Appears to be a more important outcome for patients than health professionals. Reflects quality of life, which has a substantial impact. (fatigue)

\section{Debilitating repercussions}

\section{Patients/caregivers}

A potentially devastating impact on the transplanted patient and need to be given a higher priority. (cancer-other)

Fear of having to return to dialysis is worse than fear of death. (graft loss) 


\section{Theme}

I don't know why I did not rate this higher the first time around. The thought of dialysis as a way of life is why we did a live kidney donation. Not sure how we will cope. (graft loss)

Slightly lowered my importance rating. As confidence grew in my transplant and able to enjoy a 'normal' life, depression improved. It is important as don't want to waste any more life being depressed. Need to be able to make the most of life and embrace all the new opportunities and good health. (depression)

Always concerned about the likelihood of this as a patient. It is a large and real fear. (surgical complications)

\section{Health professionals}

This is a major cause of death and impacts on how the patient feels functions survives. (infection)

Extremely important as a surrogate endpoint for severe medical problems and side effects or poor function. (hospitalization)

Critical, but relative to death cannot receive the highest rating. (graft loss)

\section{Understanding and gaining awareness of risks}

\section{Patients/caregivers}

Wasn't aware that this was a possible problem. (diabetes)

I was never aware a transplant could make one impotent. (fertility)

I have changed my score based on health professionals' judgments. (chronic graft rejection)

On second thought I find this is a really important issue, affecting quality of life and also stress related to going back on dialysis. (chronic graft rejection)

I have increased my score since last survey have done some research on this outcome and believe it is an issue that needs more investigation. (cancer-other)

Certainly can be a major risk factor, feel it needs to be rated up so people appreciate just how critical it can be to people staying healthy. (infection)

More common than I realized. (cancer - skin)

I have moved my rating to 8 because this is obviously so important to patients. (depression)

I found little to change my opinions. Where I have it's because the additional perspectives provided by everyone's comments have enlightened me. (general)

I'm finding it very instructive to learn what my fellow transplant patients' value most about renal and transplant care. My experience of the process is similar to many, but unique from some as well. Good food for thought in improving kidney care across the spectrum: there is a need to understand the patients perspective and their individual needs and goals in living with it. (round 2)

\section{Health professionals}

Important but not specific for transplant, eventually associated with complications and fear of graft loss. (depression)

Accept comments and respect importance for patients, so I have moved this to 8. (depression)

Underestimated the importance based on patient feedback. (eye problems)

Addressing critical knowledge gaps

Patients/caregivers

Research would be beneficial in providing the family/friends with the most accurate prognosis and expectations. (impact on family)

I was going to rank this with lower importance than I have but if we know answers to this we have more opportunities to find out the reasons why. This would help understanding of rejection and if anything can be done to improve survival rates. (death)

The more we know about this the more we can prevent it from happening. (graft loss)

I feel strongly that research into chronic graft loss is essential for finding new protocols and medications. (chronic graft loss)

From all the comments it is clear it is a major issue and critical to understand more in order to prevent skin cancers as well as treat it. The research may help us design education (for both health professionals and patients) and may lead to new insight. (cancer-skin)

My rating stands as research plays a big role here so they can keep ahead of these infections so the new kidney transplant is kept functioning longer. (infection)

\section{Health professionals}

This is complex but is a major problem requiring solution if we are to improve outcomes. (chronic graft rejection)

This has been a long-standing issue. Getting patients off the disability pension and into the work force after transplant is often difficult. (ability to work) 


\section{Theme}

Very critical for patient but hard to assess, needs long-term data hard to generate and information on prekidney transplantation data. (bone disease)

Very important to recognize, so that we can learn how to treat and give prognosis. (chronic graft rejection)

Key issue, not easy to address, but deserves specific research as no clear data are available on this outcome. (ability to work)

NB: In general, the comments were entered as a general comment at the end of the survey not for a specific outcome domain. 